\title{
MARIANO PICÓN SALAS: \\ EL ARTE Y LA COSTUMBRE DE PENSAR
}

POR

Alexis Márquez Rodríguez

Mariano Picón Salas "detestaba" que lo clasificasen de "ensayista". Al menos así lo daba a entender, quizás porque era alérgico a las clasificaciones, y no porque sintiese menosprecio por el género ensayístico. En uno de sus más preciosos ensayos - en él se da la paradoja de tener que escribir un excelente ensayo para rechazar su clasificación de ensayista - dice, con indisimulada y un poco burlona ironía, y aun con algo de deliciosa arrogancia, lo siguiente:

A mí ya me pusieron el título de "ensayista", lo que para muchas gentes que tengan la paciencia de leerme o la mayor paciencia de comprenderme, significaría que cada mañana que me siente junto a la máquina de escribir debo secretar un ensayo para no desmerecer de tan honrosa clasificación. El crítico o comentarista no supone que alguna vez me dé la gana de escribir un estudio histórico, un cuento o una novela o sencillamente un artículo polémico, porque también uno necesita descargar la bilis del alma y hasta romperse la cabeza y sangrar ante un problema menudo de los que no requieren tratarse en prosa platónica, sino conjurarlos con mandobles y guijarros. Parezco condenado a convertir en "ensayo" todo cuanto toco, aunque a veces aspiro a una más simple denominación de escritor que de acuerdo con lo que quiera hacer, elegirá la técnica adecuada. ${ }^{1}$

No obstante, la identificación de Picón Salas como ensayista terminó por imponerse. Lo cual no impide que se estime y se valorice su obra no ensayística. Lo predominante en sus escritos fue siempre el contenido conceptual, el oficio de pensador que se expresaba en todas las formas de escritura que practicó, y ello condujo a su clasificación fundamental como ensayista. Pero su obra ensayística, que es la mayor parte de sus escritos, posee una gran variedad de contenido y de elementos formales, por lo que su clasificación como ensayista, lejos de limitar su ubicación dentro del ámbito de los géneros, mas bien debe verse con una cómoda holgura.

Picón Salas tenía razón cuando confesaba que prefería "una más simple denominación de escritor que de acuerdo con lo que quiera hacer, elegirá la técnica adecuada". Porque si

' Mariano Picón Salas, "Y va de ensayo", Viejos y nuevos mundos (Caracas: Biblioteca Ayacucho, 1983) 501. 
bien su vasta obra fue predominantemente conceptual, como ya dijimos, y él un verdadero maestro del ensayo, la condición de escritor se hizo consustancial con su vida, fue su vida misma, pues desde muy joven la asumió como tal, y desde cuando escribió, todavía adolescente, su primer texto, ya no hubo un solo segundo en ella que no fuese vivido plenamente como tal, como escritor, independientemente del género que adoptase cada vez.

En tanto que ensayista, Picón Salas es heredero de una rica tradición venezolana, e hispanoamericana en general. Por ignorancia, o por necio afán negativista, suele impugnarse la existencia en el pasado venezolano de una literatura conceptual. Y la verdad es que nuestro siglo XIX fue fundamentalmente de pensadores y ensayistas, pues, salvo las figuras excepcionales de Andrés Bello y de J. A. Pérez Bonalde, no tuvimos en Venezuela grandes poetas en el siglo pasado, y tampoco narradores de importancia, no obstante que en ese siglo se produjo el nacimiento de los géneros narrativos en nuestro país. En cambio, tuvimos grandes cultivadores del pensamiento, que se expresaron en el ensayo, el artículo periodístico, la oratoria profana o sagrada, el género epistolar ... Figuras como Simón Rodríguez, Juan Germán Roscio, Miguel José Sanz, Fermín Toro, Cecilio Acosta, Juan Vicente González, Luis López Méndez, Rafael María Baralt, entre otros, representaron en el siglo XIX lo más brillante del pensamiento venezolano, al nivel de las grandes figuras del continente, como Martí, Sarmiento, Rodó, Hostos, Montalvo, etc. Otros, nacidos igualmente en ese siglo, llegaron hasta el presente con igual prestancia, como Lisandro Alvarado, José Gil Fortoul, César Zumeta, Laureano Vallenilla Lanz, Jesús Semprum y muchos más.

Un poco más acá en este mismo siglo, Mariano Picón Salas es la figura de mayor relieve en ese campo de las letras. Su obra es de una indiscutible trascendencia continental, y su nombre se luce entre los de valores de la alta talla de Alfonso Reyes, Pedro Henríquez Ureña, José Carlos Mariátegui, Juan Marinello, José Vasconcelos y muchos otros.

Ese predominio de la literatura conceptual sobre la imaginativa se explica por la presencia en nuestra realidad de ingentes problemas, que obligan más a la reflexión que a los escarceos imaginativos. Por ello tal predominio irá cediendo poco a poco cuando, ya en las postrimerias del siglo XIX y entrado el XX, aunque subsisten muchos de los viejos problemas, nuestros países parecen más sosegados, con algunas décadas de experiencia republicana, y puestas en marcha, si bien con grandes fallas, errores y tropiezos, las incipientes instituciones propias de repúblicas soberanas. Además, se cobra conciencia de que los nuevos problemas ya no presentan un estado tan de emergencia como los propios de la época de la independencia, y ello hace que nos vayamos acostumbrando a convivir, dentro de una especie de crisis permanente, con tales problemas, para los cuales es difícil predecir soluciones a plazo más o menos fijo. Entre esos problemas sobresalen el caudillismo y las contiendas civiles. Pero ya no se trata de una guerra iniciada con un propósito fijo y preciso, el de lograr la emancipación, lo cual permitía pensar en su fin inevitable, una vez alcanzado el objetivo, aunque no se pudiese predecir cuándo se llegarla a ello. Las guerras civiles, en cambio, engendradas por el caudillismo, parecían interminables, porque cuando concluía una, ya estaban en curso los preparativos para la siguiente. De modo que se fue creando una especie de acostumbramiento a ese ambiente, 
en el que era indispensable habituarse a combinar los menesteres de la guerra con las costumbres de la paz. De ese modo surgió la figura del intelectual que unas veces hacía la guerra, y otras se dedicaba a escribir, ya no sólo ensayos y demás textos conceptuales, sino también poemas y narraciones. Así tuvimos poetas como Francisco Lazo Martí, cuyos versos alternaban con sus recetas de médico y con sus andanzas de guerrillero, o narradores como Eduardo Blanco o Manuel Vicente Romerogarcía, que entre uno y otro fogonazo de fusiles y cañones escribían cuentos y novelas.

Pero la aparición, en las postrimerías del XIX y los albores del nuevo siglo, de una literatura imaginativa ya con signos de cierta madurez (antes hubo intentos no del todo desdeñables) no determina que desaparezca la tradición ensayística. Muchos de los poetas y narradores cultivan también los géneros conceptuales, y sigue habiendo los que sólo se ocupan de estos últimos. En el siglo XX hemos tenido en Venezuela tantos y tan buenos pensadores y ensayistas como en el XIX. Y Mariano Picón Salas es uno de los más prominentes.

Nacido en 1901 en Mérida, entonces una bucólica ciudad provinciana en los Andes venezolanos, Mariano Picón Salas dio muy tempranas muestras de excepcionales dotes intelectuales, por lo que fue enviado, casi adolescente aún, a Caracas, donde se suponía que eran más propicios el ambiente y los recursos para el desarrollo del talento y la vocación humanística. Pero pronto el muchacho comprendió que aquéllo no era como se pensaba, y que la situación excesivamente represiva, bajo la dictadura de Juan Vicente Gómez, era asfixiante para el talento y las inquietudes intelectuales. Entonces regresó a Mérida, y luego se decidió enviarlo a Chile, país lejano, pero que descollaba entre los más civilizados del continente, con una bien cimentada democracia, una educación bastante avanzada y una proximidad espiritual a Europa, no obstante la gran distancia geográfica. En Santiago vivirá Picón Salas desde 1923 hasta 1935, cuando la muerte del dictador le permite volver, acicateado, entre otros motivos, por el deseo, sentido, además, como deber, de ayudar a la reconstrucción del país sobre las ruinas dejadas por la larga tiranía de treinta y cinco años, sumando los ocho (1900-1908) de Cipriano Castro a los veintisiete (1908-1935) de Juan Vicente Gómez.

La formación universitaria de Picón Salas transcurrió, pues, en Chile, en la misma universidad diseñada por Andrés Bello para sustituir la vieja universidad colonial. Allí estudió, y luego ejerció la docencia. Fueron trece años fundamentales en su vida, pues Chile era, en efecto, un país muy avanzado, sobre todo en materia cultural y educativa. En ese ambiente halló terreno propicio el espíritu del joven venezolano para desarrollarse, con la amplitud universal que va a ser uno de los signos más notorios de su personalidad intelectual.

Estos rasgos de su espíritu se vieron luego afianzados cuando, ya de regreso en Venezuela, viaja a Estados Unidos y Europa en misiones oficiales. Fue con los ojos muy abiertos, ansioso de impregnarse de la realidad de esos países, que vivían una etapa crucial de su historia, los años inmediatamente anteriores a la Segunda Guerra Mundial vividos en medio de una crisis que ya hacía vislumbrar los horrores de la contienda. Las experiencias 
de ese viaje le dictaron a Picón Salas uno de sus libros fundamentales, Europa-América, publicado originalmente en 1937. Son una serie de ensayos sobre la relación entre los dos continentes, y en ellos se pasa revista a la situación de los países europeos en la antesala de la guerra, con el nazismo ya entronizado en Alemania y el fascismo en Italia. También se analiza en ese libro lo que entonces apuntaba como el futuro de América, a la vista de muchos intelectuales y políticos destinada a ser el refugio de la civilización, o de lo que de ella quedase después de la guerra inminente. Aparte del contenido mismo de los ensayos de este libro, del significado que tuvo para Picón Salas este viaje da testimonio muy elocuente el prólogo que él mismo escribió para la segunda edición, publicada en México en 1947. Allí dice lo siguiente:

\begin{abstract}
Para el arte de la prosa o de la arquitectura, para una tesis universitaria como para un diagnóstico médico nos era así necesario el contacto de Europa como los romanos de hace veinte siglos a pesar de su poder, seguían aceptando la norma ideal de Grecia. Los mejores espíritus de las dos Américas, de Jefferson a Bolívar, de Emerson a Rubén Darío, descubrieron lo americano presentando como supuesto previo los métodos y el instrumental europeos. De un americanismo cerrado surgían frecuentemente en nuestra producción intelectual aquellos mazacotes de quienes suponen que se puede escribir Historia del Perú o de Chile sin conocer la Historia Universal. Quien carece de punto de comparación ni siquiera ve lo próximo, y en el peor de los casos es preferible ser dilettante con los sentidos dispuestos a captar todo lo humano, que topo encerrado en su cueva sin ojos ni apetito para todo lo que no sea su cerrada especialización. Ese autoctonismo espiritual que con mayor suma de manifiestos que de obra convincente, muchos proclamaban como expresión de desafio y candorosa jactancia, consistía para nosotros en la incorporación consciente y en el otro matiz diferenciado que pudiésemos expresar en la clave común de la cultura occidental. En América se siguen hablando los viejos idiomas de Europa; Shakespeare, Cervantes y Camoens son los clásicos de nuestras dos grandes zonas continentales, y el viaje de regreso a las raíces de nuestra cultura conduce forzosamente a las playas del Mediterráneo y a la prosa platónica. (Esto, si por sobre la querella de las razas y pueblos no hubiese un legado de cultura supraétnico, supranacional.) ${ }^{2}$
\end{abstract}

Escrito diez años después del viaje, este prólogo es muy significativo, pues para el momento en que lo escribe ya en el espíritu de su autor se ha sedimentado aquella maravillosa experiencia, ya ha concluido el horror de la guerra, ya el mundo ha seguido su rumbo de relativa normalidad y la historia ha continuado su curso inexorable. Pero sobre todo es digno de observar que los efectos de ese viaje en la definitiva formación de escritor y de intelectual de Picón Salas, muy bien plasmados en las páginas del prólogo de 1947, van a perdurar en el resto de su vida y de su obra. Cualquier texto suyo nos permite hoy percibir su universalidad, su espíritu abierto e integrador, sin contradicción con su profundo americanismo, pues esa universalidad no puede confundirse con el cosmopolitismo de cierta generación intelectual, que en vez de integrar la cultura americana dentro del corpus universal de la cultura, pretendió desdibujar nuestra esencia cultural dentro de una especie de maremagnum amorfo de una supuesta cultura universal, sin rasgos definitorios de ningún tipo.

\footnotetext{
${ }^{2}$ Mariano Picón Salas, Europa-América, Cuadernos Americanos (México, 1947) 10-11.
} 
La vida de Picón Salas estuvo signada por la angustia, a veces en grado de desesperación. No en lo personal, pues su origen social y condición de intelectual de renombre y prestigio le permitieron gozar de una vida cómoda y placentera, sin que para ello haya tenido que poseer cuantiosos bienes de fortuna. Su angustia tuvo otras causas. En él hubo siempre un desajuste entre lo que pensaba, sentía, anhelaba y perseguía, y la realidad en que le tocó vivir.

Cuando sale de Chile, donde su vida había transcurrido dentro de un clima de sosiego y de refinamiento intelectual - pese a las inevitables penas, siempre lacerantes, del exilioy regresa a su patria, el mundo es sacudido por la vesania inexplicable que conduce a la Segunda Guerra Mundial. Para un hombre como Picón Salas es el fracaso de la civilización, el fracaso del hombre. Ver de cerca cómo la Europa de los máximos niveles de la cultura, del pensamiento filosófico más elevado y más profundo, de la música más sublime, de las artes en general más maravillosamente desarrolladas, cae de pronto en insólitos niveles de abyección y envilecimiento, es algo que no encuentra explicación ni siquiera en las teorías más pesimistas acerca de la conducta humana.

Picón Salas no fue, sin embargo, de los que por la vía de la angustia y la decepción desembocaron en el pesimismo existencialista. Su confianza en la inteligencia lo llevó más bien al rechazo de toda concepción pesimista, y a la seguridad de que la reconstrucción de la civilización europea sería obra de los mismos europeos: "Europa se reeducaría [escribió en el citado prólogo de 1947] volviendo a lo mejor de sí misma, releyendo en las escuelas a sus filósofos y moralistas después que pasase el estrago y la imposición oficial de leer a 'Mein Kampf'",

Esta convicción nacía, además, de la comparación entre la civilización europea y la civilización estadounidense, y del rechazo, por el conocimiento de esta última, del mesianismo americano que hizo pensar a muchos que, concluida la guerra, los Estados Unidos asumirían la tarea de reconstruir la devastada cultura europea.

Lo cierto es que para el ensayista venezolano, entre los años treinta y cuarenta la humanidad entró en una de sus más profundas crisis, no sólo en el orden económico, sino también, y con especial gravedad, en el ámbito moral. Fue, sin embargo, para él una crisis de prueba, en que el hombre pareció someterse a sí mismo a una dura y cruel confrontación, como para medir su capacidad de sobrevivencia:

... la misma Cultura europea y toda la Cultura había entrado en una hora de prueba, de tan serio desgarramiento, como acaso no lo conoció la Historia desde los días finales del Paganismo. Conspiraban contra nuestro legado espiritual fuerzas tan coléricamente iconoclastas como el espíritu de secta, y aquello que Ortega y Gasset denominó "deshumanización". No sólo la "deshumanización" del Arte sino también de la Ciencia y de todos los productos del espíritu que parecían proclamar su autonomía frente al espíritu mismo. De las manipulaciones de laboratorio o del abandono onírico del artista surreal ista, surgían monstruos que circulaban o vivían más allá del control de la conciencia fiscalizadora.

\footnotetext{
${ }^{3}$ Mariano Picón Salas, Europa-América, 12-13.
} 


\begin{abstract}
Era, paradójicamente, la última empresa faustiana y la primera gran empresa de regresión universal. Aquel cansancio de ser "cultos" y de aceptar los cánones y formas que exige toda civilización, que empezó a expresarse desde el siglo XVIII en la utopía rouseauniana, arribaba a su extrema consecuencia. Los nazis, por ejemplo, no eran los "buenos" salvajes invocados por el pensador ginebrino sino los "malos" salvajes. La liberación de la Cultura no nos devolvía, precisamente, al estado de inocencia y de dulce primitividad natural, sino al aullido del pitecantropo. Los hombres que descoyuntaban, simultáneamente, el Derecho y la Cortesía, no se ponían de acuerdo con la naturaleza maternal soñada por Rousseau, ni tañían la zampoña de todas las idealizaciones pastoriles, porque -más que al ambiente de las églogas- retornaban a una feroz prehistoria moral, anterior a todo acuerdo o contrato. Por una especie de darwinismo al revés, en lugar de avanzar hasta nuestros más refinados nietos, nos encontrábamos con nuestros bárbaros y peludos abuelos primates. ${ }^{4}$
\end{abstract}

Aquella caída en la barbarie tenía que sacudir un espíritu tan sensible como el de Picón Salas, quien de pronto recibía el impacto de una realidad que ponía en duda la inteligencia humana en la cual tanto se había confiado. Sin embargo, pese a lo catastrófico del choque, no alcanzó a destruir su fe en el hombre y su confianza en la capacidad humana para la rectificación y el robustecimiento moral.

Después de lo que él llamó su "itinerario europeo", trasvasado en lo que también él bautizó como su "angustiada crónica de estos días", Picón Salas concentra todos sus talentos y esfuerzos en la tarea de servir a su país, a sabiendas de que el servicio a la humanidad y al mundo comienza por el servicio al propio país y a sus conciudadanos.

Puso entonces en la educación sus mayores preocupaciones, convencido de que sólo por esa vía podría edificarse un país moderno partiendo de sus escombros. Como funcionario del Ministerio de Educación Nacional alienta una reforma y modernización a fondo del sistema educativo. Además, escribe a menudo, y de su pluma afanosa salen páginas que reflejan su amorosa preocupación por el futuro del país, señalan rumbos y proponen metas. El ensayista se va aquilatando en el ejercicio constante de la escritura.

Pero la realidad circundante - la inmediata, del país, y la más lejana, del resto del mundo - parece empeñada en minar aquella fe en el hombre y en la civilización. Dentro del contexto aterrador de la guerra y de sus secuelas de violencia y depredación, en Venezuela se suceden también hechos que alarman y angustian aun a los seres más equilibrados y optimistas.

El derrocamiento, mediante un golpe militar, de un gobierno légitimo y democrático, en 1945, desemboca en 1948 en una nueva dictadura, que llega hasta 1958. Son años de desilusión, de nuevas angustias, de desengaños que ven tambalear la fe y la confianza en el país, en el mundo y en el hombre, y que a veces alimentan un sentimiento de impaciencia. No entendía cómo un pueblo que en el pasado había dado muestras de un gran desprendimiento y de una innegable abnegación, hasta el punto de asumir como propia la lucha de otros pueblos por la libertad y la independencia, pasada esa hora estelar no había sabido construir su propia grandeza, y, por lo contrario, había caído en un lamentable estado de postración moral y de atraso material, en que los dirigentes sólo ambicionaban el poder para hacerse de prebendas y riqueza fácil:

\footnotetext{
${ }^{4}$ Mariano Picón Salas, Europa-América, 16-17.
} 
Casi había un contraste trágico entre la ambición y grandeza de nuestra Historia, cuando en el período de la Independencia los venezolanos ganando batallas, formando repúblicas y haciendo leyes se desparramaron por media América del Sur, y en lo que habíamos terminado siendo. Eramos un poco como Don Quijote después de su última y desventurada salida, y estábamos dispuestos a contar nuestro cuento nostálgico al bachiller, al cura y la sobrina. En nuestra literatura novelesca, hasta el Modernismo, son casi personajes insistentes la espada, el kepis y el uniforme que el abuelo o el lejano tío lucieron en Ayacucho y que se decoloraban, viejos de tiempo, desengaño y cansancio, en el desván de la casa familiar hipotecada y retrovendida. La mujer - un poco muda y resignada en la literatura venezolana hasta los días actuales- apenas forma parte del coro trágico y acompaña a llorar. Hasta los cuentos de José Rafael Pocaterra y Rómulo Gallegos, estas musas de nuestra tierra caliente guardan las flores del novio que se fue; rezan y suspiran en voz baja. Parecen los testigos y acompañantes del continuo desastre que hicieron los hombres: guerrilleros, políticos, aventureros, soñadores frustrados o simples "balas perdidas" de una familia en trance de desintegración. ${ }^{5}$

Es un verdadero desastre - la palabra que mejor resume el sentido de esa realidadlo que ha ocurrido en nuestro país, desde los tiempos gloriosos de la independencia hasta el presente, salido de la guerra, de las montoneras, del caudillismo, de las dictaduras primitivas y depredadoras, de la demagogia, del encono partidista, de la explotación irracional de los recursos naturales, de la administración del país como si fuese la hacienda de un latifundista devenido en gobernante sin las luces ni el equilibrio necesarios para ello, de la inteligencia puesta al servicio de los tiranos primitivos y semianalfabetos ... Consecuencia de ese desastre es que, a la muerte de Juan Vicente Gómez, el país padece un retraso enorme con respecto a la hora del mundo. Por ello la primera tarea que corresponde a los hombres y mujeres de la generación de Picón Salas es acelerar la marcha, poner a andar el reloj que se había detenido:

Podemos decir que con el final de la dictadura gomecista, comienza apenas el siglo XX en Venezuela. Comienza con treinta y cinco años de retardo ...

$\ldots$

Los desterrados, principalmente los jóvenes que regresan a la muerte del tirano, traen de su expedición por el mundo un mensaje de celeridad. Era necesario darle cuerda al reloj detenido; enseñarles a las gentes que con cierta estupefacción se aglomeraron a oírlos en las plazas públicas y en las asambleas de los nacientes partidos, la hora que marcaba la Historia. Con todos los defectos, abundancia y explicable impaciencia de los recién venidos, se escribe en los periódicos de 1936 el balance patético de nuestras angustias y necesidades. ${ }^{6}$

Picón Salas estaba entre esos "jóvenes que regresan a la muerte del tirano". Pero a poco su entusiasmo inicial se va a estrellar contra una dura realidad. Las cosas comienzan a marchar, es cierto, de un modo distinto de como lo habían hecho hasta entonces. La muerte del dictador provoca una reacción natural al principio de desbordamiento, inevi-

\footnotetext{
${ }^{5}$ Mariano Picón Salas, "Comprensión de Venezuela", Viejos y nuevos mundos (Caracas: Biblioteca Ayacucho, 1983) 10.

${ }^{6}$ Mariano Picón Salas, Viejos y nuevos mundos 17.
} 
table en un pueblo que había estado contenido tanto tiempo. Sin embargo, para ciertos espíritus, como el suyo, las cosas van tomando un cariz que no es el más recomendable. Aunque de ideas políticas avanzadas, Picón Salas es un hombre de naturaleza pacifista, para quien la impaciencia es mala consejera, y sólo la evolución, en medio de un clima de paz y sosiego, puede conducir sin traumas a las metas que se ansían. Es paradójico que él que comprende el atraso del país al salir de los treinta y cinco años de despotismo, y la necesidad de "echar a andar el reloj de la historia que se había detenido", según su propia metáfora, piensa al mismo tiempo que la marcha debe ser lenta, y no comprende que esa "explicable impaciencia de los recién venidos" que se expresa en los escritos periodísticos, y para la cual se muestra tolerante, es la misma que, cuando se manifiesta en la calle y por gente en quienes opera más el estímulo de las penurias y las necesidades, revienta en acciones violentas y perturbadoras.

La violencia desata la angustia de aquel espíritu hecho para el sosiego y la calma. El gran drama de Picón Salas es que le toca ser testigo de una violencia que a su país le viene por tradición, que los años transcurridos no han apaciguado en grado suficiente, y aún se manifiesta en circunstancias traumáticas que atormentan su espíritu:

Quizás los estallidos de desorden que frente a la voluntad de orden democrático siempre se produjeron en el país, sean también un sútil y complicado problema de cultura colectiva. En 150 años de vida independiente no hemos podido aprender todavía el buen juego de la política como se puede practicar en Inglaterra o en los países escandinavos. Hay que continuar civilizando la política como todas las actividades humanas, como el deporte, el amor o la cortesía. Hay que enfriar a los fanáticos que aprendieron una sola consigna, se cristalizaron en un solo "slogan" y no se afanarán en comprender y discutir lo distinto para que no se les quebrante su único y desesperado esquema. Hay que sacar a muchas gentes de las pobres fórmulas abstractas que mascullan con odio y sin análisis, para que por un proceso fenomenológico (tan característico del pensamiento contemporáneo) definan el hecho y la circunstancia concreta. Hay que acercar nuestra Cultura no sólo al siglo XX —que ya está bastante canoso— sino al siglo próximo que emerge en la inmediata lejanía, con sus promontorios y cordilleras de problemas. Contra la idea de una catástrofe y retaliación universal donde la sangre del hombre sería el combustible revolucionario, brota también en nuestra época una más humana esperanza. La Ciencia, la Técnica y sobre todo el fortalecimiento de la conciencia moral, pueden ayudarnos a ganar las nuevas batallas y aventuras del hombre sin necesidad de "paredones" ${ }^{\text {y }}$ guillotinas. ${ }^{8}$

\footnotetext{
${ }^{7}$ Es evidente que esta referencia al "paredón" alude a la Revolución Cubana, pues fue una expresión que estuvo muy en boga en los meses iniciales del triunfo revolucionario en Cuba, no obstante que, si bien hubo fusilamientos de connotados funcionarios de la dictadura de Batista, a quienes se les comprobó responsabilidad directa en asesinatos y depredaciones, no se trató de un derramamiento de sangre indiscriminado ni excesivo, como en la Revolución Francesa, a la que Picón Salas alude también con el vocablo "guillotina". Picón Salas siempre mantuvo una posición muy enemistosa y de severas reservas con la Revolución Cubana, seguramente no sólo por sus convicciones pacifistas y ajenas a todo tipo de violencia, sino también por la nefasta influencia que en él siempre ejerció, sobre todo en los años finales de su vida su gran amigo Rómulo Betancourt, líder socialdemócrata de gran sagacidad política, aunque sumamente atrasado en lo ideológico. Bajo el gobierno de Betancourt (1959-1964), Picón Salas ejerció algún tiempo la Secretaría de la Presidencia de la República.

${ }^{8}$ Mariano Picón Salas, Viejos y nuevos mundos 20.
} 
Lo admirable es que, ante aquel panorama aún conserve su optimismo, basado en la suposición de que la Ciencia, la Técnica y, sobre todo, "el fortalecimiento de la conciencia moral", es decir, la educación, podrán ayudarnos a lograr nuestro destino, sin necesidad de la violencia como recurso decisivo. Esa confianza en la educación le durará hasta el final. En uno de los ensayos de su libro Regreso de tres mundos, texto autobiográfico de hondo contenido conceptual, publicado en 1959, cinco años antes de morir, dice, en efecto:

Formar ese orden civil donde florezca la cultura y se respeten las más hermosas obras del hombre, no es solamente tarea de políticos sino de educadores y humanistas. ¡Cuántos modernos Baltazar de Castiglione nos hubieran hecho falta para enseñar siquiera ademanes, sosiego, buena conversación o mejor meditación a tantas gentes que pretendían ser dominadores de la sociedad en nuestro confuso mundo suramericano! Sólo la educación, una inmensa, repartida, inagotable educación, podría vencer los horribles desniveles de pensamiento y conducta que agrietan nuestra existencia colectiva. ${ }^{9}$

Se podrá calificar de idealista y romántica esta fe en la educación y la cultura, como antídotos contra los males de un proceso en que el signo predominante ha sido la violencia, y a través del cual se ha desembocado en una inversión de valores que va de lo grotesco a lo trágico. Nada hay de objetable en esa calificación. Pero es triste que su idealismo lo haya conducido a la angustia y, a veces, a la desesperación, al comprender que el rumbo de la historia se aparta cada vez más de ese ideal de paz, de concordia, de respeto a los valores más puros y nobles, y pareciera demostrar que el desideratum de felicidad y progreso social que impulsa al hombre a su tarea de cada día, sólo es alcanzable mediante la violencia y el dolor.

Picón Salas no ignoraba el contenido idealista de su posición. Él mismo calificó de utopia su pensamiento: "El país es hermoso y promisorio [dijo alguna vez de su patria] y vale la pena que los venezolanos lo atendamos más, que asociemos a su nombre y a su esperanza nuestra inmediata utopía de concordia y felicidad". ${ }^{10}$

Ese idealismo, además, hizo que al final se mostrase poco dado a la comprensión de los fenómenos sociales que marcaron, con su violencia y sus vientos huracanados, los últimos años de su vida, en un país al cual amaba entrañablemente. Los años sesenta, en Venezuela y en casi todo el resto de América Latina $-\mathrm{y}$ aun en casi todo el mundoestuvieron marcados por luchas violentas, en que el signo predominante era el furor de los sentimientos más primitivos. El empeño de las fuerzas de izquierda, catalizadas por el triunfo de la Revolución Cubana en 1959, por arrebatar el poder de manos de la burguesía, provocaron en nuestros países un gran incendio, en que se consumieron miles de jóvenes, y los ideales más altos y sublimes que el hombre había venido acumulando a lo largo de los siglos.

La violencia fue de parte y parte, pues si bien quienes pretendían el derrocamiento del poder burgués apelaron a la lucha armada, más de una vez desviada hacia el terrorismo, de igual modo se desató un verdadero terrorismo de estado por parte de las fuerzas represivas policiales y militares. Picón Salas murió en esos días trágicos, justo a mitad de la década

9 Mariano Picón Salas, "Regreso de tres mundos", Viejos y nuevos mundos 620.

${ }^{10}$ Mariano Picón Salas, "Comprensión de Venezuela", Viejos y nuevos mundos 21. 
amarga, cuando la violencia y el desasosiego alcanzaban en su país las cotas más altas, sin que la muerte le diese tiempo para presenciar la derrota de la subversión de izquierda, y el afianzamiento definitivo de la democracia burguesa, en la cual creía con sinceridad, y a cuya orientación ideológica y edificación práctica él había contribuido, desde una definida ubicación socialdemócrata.

Esta identificación ideológica, en su caso, representaba una posición avanzada, que le venía por herencia de sus abuelos liberales. Pero en él tenía, además, un aderezo intelectual, que lo llevaba a aquella incomprensión del signo violento y trágico de las luchas políticas y sociales que le tocó presenciar. El entendía muy bien el concepto de revolución, y consideraba justo que ése fuese el objetivo de toda lucha por la redención popular y la construcción de una nueva sociedad, sin explotadores ni explotados. Pero no concebía esa revolución sin el imperio, en su seno mismo, de la decencia, de la bondad, incluso de la cortesía en la relación entre gentes civilizadas, aun cuando se tratase de personas enfrentadas en la lucha revolucionaria.

Sobre el concepto de revolución habló muchas veces, e incluso escribió un ensayo, "La palabra revolución", incluido también en su libro Regreso de tres mundos. Allí define su posición ante al fenómeno revolucionario, que, aparte de haber alentado en el hombre desde tiempos inmemoriales, así fuera como mera intuición, había adquirido a partir de cierto momento una jerarquía avasallante, incluso como teoría ideológica, por encima de muchos otros conceptos y valores de la civilización contemporánea.

A partir de la Revolución Rusa de 1917, en efecto, el sentimiento revolucionario había rebasado todo interés humano, y alcanzó, según palabras de Picón Salas, una "vibrante vigencia explosiva en los años que precedieron a la segunda Guerra Mundial". Ese fue, en consecuencia, uno de los signos más notorios del período de la historia que le tocó vivir a nuestro gran ensayista.

Ahora bien, él percibia un marcado contraste entre lo que entendía por revolución, y lo que la praxis cotidiana mostraba ante sus ojos. Para él había en el concepto de revolución una pureza y una carga humanística enormes, y no concebía cómo en nombre de un ideal tan noble como ése, podían cometerse lo que a su modo de ver eran graves atentados contra la civilización misma, y sobre todo cómo podían adoptarse comportamientos que implicaban un desenfadado desprecio por ciertos valores que, para él, eran consustanciales con el concepto de hombre, de ser humano: "la idea de Revolución [escribió en el ensayo mencionado] era para mí llegar mucho más lejos que a aquel hermético paraíso de bronce en que se trocó la llamada dictadura del proletariado". Y a renglón seguido agregó, para ampliar y precisar esa idea, lo siguiente:

Mi choque con los sectarios fanáticos, los gélidos hombres de partido a quienes solía encontrar en cafés y reuniones nocturnas ofreciendo las teorías del último folleto, procedía del amor a la justicia y de la casi imposible pureza que asociaba a la palabra "Revolución". Mis estudios universitarios de Filosofia estaban impregnados de moral kantiana. Y no concebía - acaso con rigidez opuesta - ningún movimiento político sin imperativo categórico. No me importaba el reparto comunitario de los bienes de la tierra; que como 
en la Utopía de Tomás Moro nos cambiásemos en un armonioso mercado común lo que producíamos, y yo daría clases o escribiría libros o artículos a cambio de un traje, unos zapatos o unas libras de café, pero disfrutando todos de nuestro derecho al sol y al aire; de pensar y escribir lo que nos soplase la imaginación. ${ }^{11}$

Es obvio que en esta idea de la revolución está la base del idealismo que ya señalamos en Picón Salas. El lo dice de manera expresa, cuando confiesa que su idea de revolución se asocia con una "casi imposible pureza". Dramáticamente, esa concepción se torna en angustia y desesperación cuando la compara con la realidad que le ofrecen las revoluciones que se han venido produciendo en el mundo.

Cabría preguntarse si este modo de entender la palabra revolución, y el correlato que subyace en su médula, era sincero, o, por lo contrario, no pasaba de ser la habilidosa cobertura de un pensamiento reaccionario. Es indudable que tal concepción se nutría de una valoración del hombre y de la vida de típico signo burgués, pero no en el sentido crematístico y pragmático en que este término ha devenido, sino en el de los altos ideales del humanismo. El conocimiento personal y muy de cerca que tuvimos de él por una parte, y el examen cuidadoso de sus escritos nos permiten asegurar que era sincero, que en efecto creía en la revolución como el instrumento necesario para que el hombre hallara el camino definitivo de su progreso y su felicidad, y, lo que es más, que tenía el firme convencimiento de que la transformación revolucionaria de la sociedad capitalista era indispensable para el logro de esos ideales.

Nada, pues, más alejado de una posición reaccionaria que su pensamiento político. Su inequívoca censura del capitalismo demuestra que para él el problema del mundo contemporáneo no era simple cuestión de comportamiento individual o colectivo, que la psicología científica podría corregir. Era una cuestión de sistemas, de la necesidad de transformar desde la raíz el sistema de vida y de producción que impera en la sociedad capitalista, porque en la base de la misma está el fundamento irreparable de su injusticia y de su perversidad.

Los primeros enjuiciamientos que hace Picón Salas del sistema capitalista están en su libro Europa-América. Allí reseña su primer viaje a los Estados Unidos con un descarnado sentido satírico, que a veces pasa de lo irónico a lo sarcástico. La comparación que hace de ese país con la Europa que, aunque severamente herida por el nazismo y el fascismo, por la claudicación de las democracias burguesas al dar la espalda a la España republicana y por la guerra, sigue siendo para él la cuna del humanismo, "el mundo de la Cultura, de todas aquellas cosas imponderables y exquisitas que nos dan los libros franceses o las piedras y las pinturas italianas, el paisaje histórico que poblamos de sueños", ${ }^{12}$ esa comparación conlleva implícita una condena radical de una forma del capitalismo que, aunque ha nacido en Europa, ha tomado de ésta sólo los elementos económicos del maquinismo y la Revolución Industrial, y los ha llevado al máximo refinamiento, pero se ha despojado de los valores intelectuales del humanismo y la filosofía burguesa, trocada ésta en un grosero pragmatismo de predominante expresión crematística.

\footnotetext{
"Mariano Picón Salas, Regreso de tres mundos 590-591.

${ }^{12}$ Mariano Picón Salas, Europa-América 27.
} 
Su fe en los valores humanísticos de la cultura europea lo lleva, incluso, a prever para la Alemania de 1937, envilecida por el nazismo, la posibilidad de salir de su profunda crisis con la sola vuelta a sus principios morales e intelectuales. En el ensayo titulado "Meditación alemana", del citado libro Europa-América, dice estas palabras que, escritas en 1937, resultan proféticas:

Para volver a ocupar su sitio de preeminencia dentro de la Civilización occidental, Alemania tendrá que leer de nuevo a Goethe y a Kant, olvidando las necias declamaciones de Rosenberg, que es el filósofo privado del Fürer. Aprenderá otra vez en sus grandes espíritus que lo "germano" no tiene por qué oponerse a lo "clásico" y a lo "cristiano"; que - como en el símbolo profundo de Goethe puede otra vez realizarse en obsequio de la unidad de Europa, el matrimonio de Fausto y Helena. ${ }^{13}$

Pero no se crea que este enjuiciamiento descarnado del capitalismo, tomando como modelo la sociedad de los Estados Unidos, fue sólo un juvenil acto ritual, al que parecen sentirse obligados todos los intelectuales y los políticos latinoamericanos antes de los treinta y cinco o los cuarenta años. Dos décadas después de aquellas palabras de 1937, en el mencionado ensayo "La palabra Revolución", reitera y aun amplía y fortifica su argumentación contra el capitalismo como sistema deshumanizado que, en vez de hacer la felicidad del hombre mediante una justa distribución de las riquezas producidas por su esfuerzo y su inteligencia, más bien acentúa las desigualdades, acrecienta la miseria y afianza las injusticias sociales, al par que esteriliza la espiritualidad consustancial con la condición humana. Aun sin estridencias ni radicalismos, las palabras de Picón Salas son precisas e inequívocas:

Traduciendo mi sentimiento juvenil de aquellos días, "Revolución" se llamaba lo que transformaría progresivamente los males de la sociedad. Que hubiera menos miseria; que la máquina - ya no monopolizada por el capitalismo - aliviará la pesada carga de agobiante trabajo manual que aún pesa sobre las masas proletarias; que no hubiera gentes sin nutrición, vivienda y vestido, y no sólo las minorías adineradas o subvencionadas tuvieran derecho a la educación y la cultura. En nuestro mundo suramericano, servilmente atado a las grandes potencias que imponen al mundo sus sistemas de economía y estilo de vida, tan soñada Revolución formaba parte de un inconcluso capítulo de la Independencia nacional que no terminó cuando Bolívar y Sucre dieron en el Perú las últimas batallas contra los españoles; los diplomáticos firmaron en Madrid y Londres tratados de paz y comercio recíproco; o cuando Mr. Monroe quiso proteger las Américas de las posibles agresiones de la Santa Alianza. Pero ¿no trabajamos todavía como siervos coloniales para las grandes potencias y los consorcios; no les entregamos todas nuestras materias primas para que ellos las transformen, manufacturen y vendan; no pagamos a precio de usura las líneas de ferrocarril y los empréstitos que nos concedieron? ¿No levantaba el desarrapado "roto" chileno sus lingotes de cobre, y el ovejero de Patagonia sus libras de lana, para que se las llevaran por poco precio las foráneas empresas inversionistas? Aquel capitalismo erigido sobre pirámides de universal miseria ¿no apoyaba dictaduras y regímenes de fuerza en casi toda la América Latina para que las masas no pidieran más alfabeto, más salario o más comida? ${ }^{14}$

\footnotetext{
${ }^{13}$ Mariano Picón Salas, Europa-América 59.

${ }^{14}$ Mariano Picón Salas, Regreso de tres mundos 591.
} 
El problema es que aquella fe en la revolución, como instrumento que debería librarnos de las injusticias e iniquidades del capitalismo, terminó en frustración. Porque si bien las revoluciones realizadas en algunos países dotaron a muchos pueblos de mejoras sustanciales en las condiciones de vida y de trabajo, el precio por ello fue un nuevo estrangulamiento de las libertades ciudadanas, que para un espíritu tan liberal como Picón Salas eran sustanciales e imprescindibles en una sociedad, aunque en ésta se garantizase el disfrute de ciertos derechos, como la salud, la educación y el trabajo remunerador.

De manera que el mundo se vio como cogido en las pinzas gigantescas de una doble frustración: de un lado el capitalismo deshumanizado —capitalismo salvaje lo ha llamado recientemente el papa Juan Pablo II- y del otro, la contraparte de una sociedad salida de una revolución cuyos principios humanísticos no llegaron a realizarse, y por ello no pasó de ser, según sus palabras, "aquel hermético paraíso de bronce en que se trocó la llamada dictadura del proletariado".

Ubicado dentro de los esquemas de la socialdemocracia, Picón Salas fue uno de los intelectuales venezolanos más catastróficamente afectados por las terribles desviaciones del estalinismo. En él fue una posición sincera y honesta, y no, como en muchos otros, una grotesca coartada oportunista para desertar de lo que antes fueron y pensaron, ni para dar un salto mortal hacia posiciones que les garantizasen prebendas materiales, y la benevolencia de aquellos poderosos a los que antes denunciaron y combatieron. Lo de Picón Salas no fue el clásico "pasarse al enemigo", en busca de hacerse perdonar arrestos juveniles de iconoclasia y de ardorosos radicalismos. Para él la cuestión era mucho más seria, y fundamentalmente honesta. Se trataba de que el fracaso de un ideal revolucionario había significado a la larga la más trágica paradoja de la historia: "Que la anunciada revolución con que soñaban los socialistas humanitarios del siglo XIX [escribió en otro de los ensayos de su Regreso de tres mundos] no logró la libertad intelectual, sino quiso implantar, por el contrario, un mundo más limitado y más tonto, es la horrible paradoja de nuestra época". ${ }^{15}$ Estas palabras, y muchas otras del mismo o parecido tenor, han tenido una dramática reactualización en los años recientes, que han visto desmoronarse el mundo edificado en nombre de esa revolución, destruido, no precisamente por los poderosos enemigos que lo combatieron desde siempre, sino por los insólitos errores de sus propios constructores.

Lo más lamentable es que ese idealismo, en esencia hermoso y encomiable, lo encerrase en algunas incomprensiones que lo llevaron a confundir unas cosas con otras. Podría concedérsele alguna indulgencia a la identificación del nazismo con el llamado socialismo real, flagrantemente antihistórica aun a pesar de los excesos del estalinismo. Pero resulta muy cuesta arriba otorgarle comprensión a la que pretende atribuirle, así sea por vía de insinuación, la misma naturaleza a la lucha de los fascistas franceses de la OAS contra de Gaulle, por su actitud favorable a la independencia de Argelia, y a la del ELN argelino que combatia por su libertad y su soberanía. La elegancia conque está escrita la página que

${ }^{15}$ Mariano Picón Salas, "Visita a los malos salvajes", Viejos y nuevos mundos 496. 
sigue, en que evoca sus días parisienses, no excusa su confusión y su inconsistencia ideológica:

Cada día de esta primavera me gusta salir temprano de casa; recorrer mi barrio, comprar contradictorios perí́dicos y mirar y reflexionar las inscripciones que dejaron en las murallas esos militantes políticos que ejercen una especie de periodismo insomne y anónimo. De los clandestinos clubes activistas se difunden en organizado secreto las consignas que despertarán a los parisienses junto con la leche y el "croissant" del desayuno. El odio, más que el amor, se expresa en estos "grafitos" urbanos, pues si algún fervoroso adolescente pudo escribir allí un "Viva Brigitte Bardot" predominan más los "mueras" y los "abajos". Ahí emergen para el sociólogo las palabras de ese deseado "Diccionario moderno" de la mentira que debe completar al "moderno Larousse". Porque el presidente De Gaulle dijo que el destino de Argelia en un momento en que todo colonialismo está muriendo debe resolverse por la "autodeterminación de los argelinos", lo que es tan sólo la aplicación honestísima de la muy francesa, democrática y universal teoría de la soberanía del pueblo, los rabiosos "ultras" que manchan las murallas del barrio, lo comparan con el señor Thorez, conocido y anciano jefe del partido comunista. Escriben, por ejemplo, "De Gaulle = Thorez" o "la cruz de Lorena (conocido símbolo usado por el General durante la resistencia francesa) = la hoz y el martillo". "Libérez les patriotes", "Liberad los patriotas" significa para la misma enfurecida extrema derecha que no debería haber procesos ni justa reclusión para los que se amotinaron contra el gobierno legítimo y colocaban en casas y servicios públicos algunas cargas de "plastic".

Este barrio (contra mis gustos de ciudadano sencillo) es orondamente burgués y parece haber sido elegido preferentemente por los "ultras" activistas para su guerra de murallas, pero si pasáramos a una de sus calles pobres, pintorescas y camorristas donde suelen vivir los argelinos, las palabras y consignas cambiarían de significación. Los "patriotas" (palabra tan repetida por la derecha y por la izquierda) ya no serían los amotinados franceses contra el gobierno, sino los grupos árabes más radicales que practicaban otra especie de terrorismo. ¿Quiénes son, pues, los patriotas?, cabe inquirir con el mayor escrúpulo semántico al pasar de una zona a otra de París. ${ }^{16}$

El error reside en creer demasiado al pie de la letra que el valor semántico de las palabras estriba en la condición de quien las emplee. Ello es cierto en muchos casos, pero la inteligencia del lector le permite distinguir cuándo el vocablo conserva su valor intrínseco, y cuándo se trata de un valor connotativo. El patriotismo de quien lucha por la libertad e independencia de su pueblo no puede ser mayor o menor, según los métodos que emplee en esa lucha, aunque éstos puedan ser equivocados y dignos de condenación. Y resulta inexplicable que para un demócrata, que ha demostrado además ser en extremo sensible frente al valor humano de la libertad, no haya siquiera un matiz de diferencia entre el patriotismo indiscutible del luchador por la libertad de su patria —el de los argelinos, qué duda cabe - y el sedicente patriotismo de quienes pretenden cercenar esa libertad, aun en contra de la voluntad mayoritaria de su pueblo, e impulsados, antes que por sentimientos de verdad patrióticos, por intereses egoístas y de dudosa moralidad social.

Hay en esto una contradicción, y las hubo muchas otras veces en el ideario de Mariano Picón Salas. Mas ello no debe sorprendernos, ni llevarnos a la condena irracional de todo

\footnotetext{
${ }^{16}$ Mariano Picón Salas, Viejos y nuevos mundos 495.
} 
su pensamiento, pues en el mundo convulsionado y desconcertante en que nos ha tocado vivir, la contradicción, cuando está sustentada en la sinceridad y la honradez, como en su caso, y no en el oportunismo, parece ser uno de los signos de mayor vitalidad del hombre contemporáneo. Por lo demás, en el balance que hoy podemos hacer de la vida, el pensamiento y la obra de Mariano Picón Salas, pesa mucho más lo positivo que lo negativo. 
